with autoimmune inflammatory rheumatic diseases. Ann Rheum Dis 2011;70:414-22.

[2] MTT Nguyen, H Lindegaard, O Hendricks \& N Friis-Møller. Factors associated with influenza and pneumococcal vaccine uptake among rheumatoid arthritis patients in Denmark invited to participate in a pneumococcal vaccine trial (Immunovax_RA), Scandinavian Journal of Rheumatology $2017 ; 1-8$.

Disclosure of Interests: None declared

DOI: 10.1136/annrheumdis-2020-eular.4109

\section{AB1142 DISEASES IN SUB-SAHARAN AFRICA: A CASE FOR IMPROVED INSURANCE COVERAGE FOR AFRICAN PATIENTS}

A. Akpabio ${ }^{1}$, C. $\mathrm{Nga}^{2}$, I. Umoh ${ }^{1}$, O. Ita ${ }^{1} .{ }^{1}$ University of Uyo Teaching Hospital, Internal Medicine, Uyo, Nigeria; ${ }^{2}$ University of Uyo Teaching Hospital, Uyo, Nigeria

Background: Rheumatic diseases lead to substantial economic costs ${ }^{1}$ especially in resource-poor settings like sub-Saharan Africa (SSA). ${ }^{2}$ Annual direct cost of lupus treatment ranges from $\$ 13,735-20,926$ /patient in the US to $£ 3231$ (\$4232)/patient in the UK..$^{1,3}$

Data is rare for SSA and Nigeria in particular where the minimum wage is $\mathrm{N} 30,000$ ( $\$ 83 / \mathrm{mth})$ with only $5 \%$ of citizens covered by health insurance. ${ }^{4,5}$ The scheme excludes some medications and certain procedures are grossly underfunded. Cost-of-illness studies are invaluable in planning and policy development. They typically include: direct, indirect and intangible costs. ${ }^{6}$

Objectives: To compare total costs of some rheumatic diseases, highlight underfunded therapies and push for wider insurance coverage of rheumatic diseases. Methods: A cross-sectional study from the University of Uyo Teaching Hospital - Nigeria using data of 252 clinic patients (20 lupus, 27 rheumatoid arthritis, 25 gout and 180 osteoarthritis). Direct costs were estimated using the hospital pricelist while indirect costs were estimated using the human capital method. Statistical analysis was done with $\mathrm{p}<0.05$.

Results: Females were the majority except for gout patients (44\%). Most lupus patients were unemployed $(75 \%)$ and had the highest annual total cost (N472,800-2,240,400) compared with the others. Key medications excluded from insurance are shown in table 2.

TABLE 1. COST-OF-ILLNESS COMPARISON OF SELECTED RHEUMATIC DISEASES

\begin{tabular}{lcccc}
\hline & Lupus $(\mathrm{n}=20)$ & $\mathrm{RA}(\mathrm{n}=27)$ & Gout(n=25) & $\mathrm{OA}(\mathrm{n}=180)$ \\
\hline Age (years) & $33.9 \pm 11.4$ & $43.4 \pm 14.3$ & $57.4 \pm 9.6$ & $59.7 \pm 9.1$ \\
Female $\mathrm{n}(\%)$ & $24(95)$ & $25(92)$ & $11(44)$ & $157(87)$ \\
Average Duration of illness (years) & $4(1-11)$ & $3.5(2-10)$ & $3(0.2-8)$ & $4(0.1-20)$ \\
Unemployed $\mathrm{n}(\%)$ & $15(75.0)$ & $19(70.3)$ & $12(48.0)$ & $62(34.4)$ \\
Workdays missed/mth & 7 & 5 & 2 & 3 \\
Direct costs (N'000) & & & & \\
Total /mth (stable) & 32.4 & 27 & 19.75 & 18 \\
Total /yr (stable) & 388.8 & 324 & 237 & 216 \\
Total /mth (severe) & 179.7 & 155.6 & 32.5 & 23 \\
Total /yr (severe) & $2,156.4$ & $1,867.2$ & 390 & 276 \\
Indirect costs & & & & \\
Productivity loss/mth & 7 & 5 & 2 & 3 \\
Productivity loss/yr & 84 & 60 & 24 & 36 \\
Total costs/mth & $39.4-186.7$ & $32-160.6$ & $21.75-34.5$ & $21-26$ \\
Total costs/yr & $472.8-2,240.4$ & $384-1.927 .2$ & $261-414$ & $252-312$ \\
& & & & \\
\end{tabular}

$1 \$=360$ Nigerian Naira (NGN), $1 €=$ NGN 402 as at 31/1/2020. Costs quoted in thousands of Naira.

Table 2. Uninsured treatments.

MMF

Methotrexate

Sulphasalazine

Azathioprine

$\mathrm{HCQ}$

Febuxostat

Colchicine

Rituximab

Arthroplasty (N100,000*)

Dialysis (6 sessions)

Renal transplant

Conclusion: Total annual cost of lupus treatment in Nigeria is quite high ranging from (NGN 472,800-2,242,400) [\$1313-6228] for mild to severe disease. This contrasts with a mean annual national income of $\$ 1,000$ given that $75 \%$ of lupus patients are unemployed. Expanded insurance coverage for rheumatic drugs will further reduce the enormous treatment burden and improve outcomes.

References:

[1] Slawsky KS et al. A structured literature review of the direct costs of Adult SLE in the US. Arthritis Care Res 2011:63(9); 1224-32.

[2] Adelowo OO. Connective tissue diseases: challenges of management among Nigerians. Annals of Health Research. 2016: 2(2);60-65.

[3] Khamashta $\mathrm{M}$ et al. The cost of care of SLE in the UK: Annual direct costs for adult SLE patients with active autoantibody disease. Lupus 2013:23(3):273-83

[4] Uzochukwu BSC et al. Health care financing in Nigeria: Implications for achieving universal health coverage. Nigerian Journal of Clinical Practice. 2015;18(4):437-44

[5] Nigerian National Minimum Wage. https:/tradingeconomics.com/nigeria/ minimum-wages Accessed (31/01/2020)

[6] Zhu TY et al. Cost of illness studies in systemic lupus erythematosus: a systematic review. Arthritis Care Res. 63: 751-760

Acknowledgments: All study participants, Drs Marvelous Ibanga and Eke Ogudu.

Disclosure of Interests: None declared

DOI: 10.1136/annrheumdis-2020-eular.6434

\section{AB1143 BURDEN OF GLUCOCORTICOIDS AMONG RHEUMATOID ARTHRITIS PATIENTS AT DIFFERENT STAGES OF DISEASE-MODIFYING ANTIRHEUMATIC DRUG MANAGEMENT}

R. K. Dore ${ }^{1}$, J. Antonova ${ }^{2}$, M. Gorritz ${ }^{3}$, L. Chang ${ }^{2}$, H. Xie ${ }^{3}$, M. C. Genovese ${ }^{4}$. ${ }^{1}$ Robin K. Dore, MD, private practice, Tustin, United States of America; ${ }^{2}$ Gilead Sciences, Inc., Foster City, United States of America; ${ }^{3}$ IQVIA, Plymouth Meeting, United States of America; ${ }^{4}$ Stanford University, Division of Immunology and Rheumatology, Stanford, United States of America

Background: EULAR and ACR guidelines recommend a treat-to-target approach for patients with RA including regular assessments of disease activity. Glucocor ticoids are commonly used to control inflammation associated with uncontrolled disease. However, patients using glucocorticoids may develop short- and longterm side effects.

Objectives: To examine the real-world use of glucocorticoids among patients with RA who are disease-modifying antirheumatic drug (DMARD)-naïve or failing their first conventional synthetic DMARD (csDMARD) or biologic DMARD (bDMARD). Methods: From a large US health claims database, this study included adults with $\geq 2$ RA claims $\geq 30$ days apart who started (index date [ID], 1/1/2012-3/31/2017) a first DMARD (DMARD-naïve) or patients who newly initiated a csDMARD and then switched to or added another DMARD (csDMARD switchers), and patients who initiated a first bDMARD and then switched to another bDMARD or Janus kinase inhibitor (JAKi; bDMARD switchers). All patients had continuous enrollment 1-year before and $\geq 1$ year after ID and were evaluated for pre- and post-ID use of glucocorticoids (oral or injectable), prednisone equivalent dose (PED) and duration of exposure $\geq 30$ days.

Results: The study included 28,201 patients in the DMARD-naïve cohort, 7,816 csDMARD switchers, and 4,656 bDMARD switchers (median age 54 years for all, $73 \%-78 \%$ female).

Among DMARD-naïve patients, $66.5 \%$ used glucocorticoids during the pre-ID period (Figure 1) and $61.2 \%$ had $>7.5 \mathrm{mg} /$ day PED, $21.2 \%$ had $>30 \mathrm{mg} /$ day PED, and $21.2 \%$ had $\geq 30$ days of exposure to glucocorticoids (Figure 2 ). Post-ID, $69.4 \%$ of patients used glucocorticoids, while $54.7 \%$ had $>7.5 \mathrm{mg} /$ day PED, $13.5 \%$ had $>30 \mathrm{mg} /$ day PED, and $44.9 \%$ had $\geq 30$ days of exposure to glucocorticoids.

Among csDMARD switchers, $84.5 \%$ of patients used glucocorticoids during the pre-ID period (Figure 1), and $73.4 \%$ had $>7.5 \mathrm{mg} /$ day PED, $16.0 \%$ had $>30 \mathrm{mg} /$ day PED, and $56.4 \%$ had $\geq 30$ days of exposure to glucocorticoids (Figure 2). During the post-ID treatment, $74.1 \%$ of patients used glucocorticoids, $56.2 \%$ had $>7.5 \mathrm{mg} /$ day PED, $14.4 \%$ had $>30 \mathrm{mg} /$ day PED, and $45.8 \%$ had $\geq 30$ days of exposure to glucocorticoids.

Among bDMARD switchers, $85.1 \%$ of patients used glucocorticoids in the pre-ID period (Figure 1), and $70.2 \%$ had $>7.5 \mathrm{mg} /$ day PED, $17.4 \%$ had $>30 \mathrm{mg} /$ day PED, and $55.2 \%$ had $\geq 30$ days of exposure to glucocorticoids (Figure 2). During post-ID treatment, $75.4 \%$ of patients used glucocorticoids and $59.7 \%$ of patients had $>7.5 \mathrm{mg} /$ day PED, $16.7 \%$ had $>30 \mathrm{mg} /$ day PED, and $45.6 \%$ had $\geq 30$ days of exposure to glucocorticoids. 